\title{
Parconazole Hydrochloride
}

\author{
National Cancer Institute
}

\section{Source}

National Cancer Institute. Parconazole Hydrochloride. NCI Thesaurus. Code C66317.

The hydrochloride salt form of parconazole, a broad spectrum imidazole derivative with antifung al activity. Although the exact mechanism of action has yet to be fully elucidated, parconazole, like other azole antifungals, most likely inhibits the cytochrome P450 dependent 14 alpha demethylation of lanosterol. This prevents the synthesis of ergosterol which is a crucial component of the fungal cell membrane. By disrupting fung al cell membrane synthesis and integrity, parconazole alters fung al cell membrane permeability, promotes loss of essential intracellular components and eventually inhibits fungal cell growth. 